УДК 612.6 .05

\title{
СРАВНИТЕЛЬНАЯ ОЦЕНКА УРОВНЯ СТИГМАТИЗАЦИИ СЕЛЬСКИХ И ГОРОДСКИХ ОБУЧАЩИХСЯ КАК КРИТЕРИЙ НЕБЛАГОПРИЯТНОГО ВОЗДЕЙСТВИЯ ТЕХНОГЕННОГО ЗАГРЯЗНЕНИЯ
}

\author{
Ибрагимова Э.Э.
}

ГБОУ ВО РК «Крымский инженерно-педагогический университет», г. Симферополь, Российская Федераиия, e-mail: evelina biol@mail.ru

В статье представлены данные сравнительной оценки уровня стигматизации студентов, рожденных и выросших в городской и сельской местности. Установлены статистически значимые отличия как по частоте встречаемости малых аномалий развития у обследованных студентов, так и по уровню стигматизации. В частности, в группе городских обучающихся частота встречаемости малых аномалий развития составила $67.27 \%$, у сельских $-52 \%$. Средний уровень стигматизации в первой группе составил $3.71 \pm 0.43$, во второй $-2.10 \pm 0.24(\mathrm{p}<0.05)$.

У обследованных студентов имели место отличия и по количеству выявленных дисгенезий. Так в группе городских студентов было обнаружено 34 вида малых аномалий развития, а в группе сельских - 28 видов соответственно. Наиболее распространенными дисгенезиями у городских студентов оказались аномалии конечностей, спины, ушей и зубов. Разновидности малых аномалий развития сельских обследуемых несколько отличались, так как в данной группе наиболее характерными оказались аномалии конечностей и зубов. Статистически значимые отличия показателей частоты встречаемости малых аномалий развития у городских и сельских обучающихся позволили прийти к заключению, что городская среда, отличающаяся более высоким уровнем техногенного загрязнения, оказывает выраженное неблагоприятное воздействие на перинатальный этап развития организма.

Полученные данные свидетельствуют о том, что время закладки и формирования структур опорно-двигательной системы является очень уязвимым периодом перинатального онтогенеза к негативному влиянию экзогенных факторов.

Ключевые слова: малые аномалии развития, студенты, городские, сельские, конечности, ушные раковины, перинатальный онтогенез, стигмы дизэмбриогенеза, дисгенезии.

\section{Введение}

С каждым годом темпы загрязнения окружающей природной среды возрастают, что приводит к трудно разрешимым экологическим проблемам. С одной стороны, происходит интенсификация и глобализация воздействия человека на природу, что связано с необходимостью развития энергетической базы, промышленного и сельскохозяйственного производства, а с другой - интенсификация жизнедеятельности человека неизбежно увеличивает количество трудно утилизируемых отходов, накопление которых отрицательно сказывается на благополучии биосферы и ставит под угрозу здоровье человека и его генофонд. Следовательно, антропогенное воздействие на биосферу в результате активизация хозяйственно-производственной деятельности человека, создает ситуацию острого экологического кризиса. В этой связи важное значение приобретают необходимые меры по предотвращению экологического кризиса в каждом конкретном регионе страны. К сожалению, проблема антропогенного загрязнения окружающей природной среды актуальна и для Крыма - одного из основных регионов отдыха человека (Шибанов, 2006). До 70-80\% загрязнений атмосферы Крыма приходится на автотранспорт, выхлопные газы которого составляют продукты полного и неполного сгорания топлива автомобилей (Экология Крыма, 2003) и поставляют в воздух более 200 различных веществ (География Крыма, 2001).

В последние годы отмечается снижение уровня здоровья населения Крыма. Загрязнение воздушного бассейна, гидросферы и педосферы приводит к конфликту 
между биологической составляющей человека и его средой обитания, что сопровождается развитием патологических изменений в организме, которые в большинстве своем представляют собой врожденные отклонения строения органов от нормальной физиологической организации, фенотипически проявляющиеся в виде больших и малых аномалий развития (БАР, МАР). Причинами их развития могут быть проблемы экологии, отягощенная наследственность, психологические расстройства, тератогенное действие некоторых препаратов и веществ, нездоровый образ жизни беременной женщины и многие другие. Установлено, что частота встречаемости малых аномалий развития выше, чем больших пороков, при этом отмечается, что МАР идентифицируются как у больных, так и у здоровых людей, однако чаще у больных индивидуумов (Ходос, 1984). Следовательно, количественный анализ МАР может служить информативным методом прогноза и оценки физического, нервнопсихического и социального развития индивидуума (Хацкель, Клиценко, Павлов, 2012).

Увеличение частоты встречаемости стигм дизэмбриогенеза, в том числе и у здоровых индивидуумов обусловило цель настоящей работы, которая заключалась в сравнительной оценке уровня стигматизации сельских и городских жителей, так как урбоэкосистемы отличаются более высокой техногенной нагрузкой (Ибрагимова, 2008). Следовательно, сельские жители проживают в более благоприятных, с экологической точки зрения, условиях.

\section{Материалы и методы}

В соответствии с целью исследования в эксперименте на основе принципов Хельсинкской декларации (2013), на добровольной основе приняли участие студенты Крымского инженерно-педагогического университета факультета психологии и педагогического образования $(\mathrm{n}=105$, возраст 18-21 лет), которые в соответствии с местом рождения и проживания были разделены на две группы: 1) городские $(\mathrm{n}=55)$; 2) сельские $(\mathrm{n}=50)$.

У студентов обеих групп оценивали фенотип на наличие стигм дизэмбриогенеза и определяли уровень стигматизации. Путем физикального осмотра обследуемых выявляли малые аномалии развития альтернативной группы, в частности (Бутвиловский, Бутвиловский, Давыдов, 2010):

череп: ассиметричный, долихоцефалический, выступающий затылок, черепнолицевая асимметрия, микрогнатия, макрогнатия, неправильный прикус, дефекты челюсти.

глаза: монголоидный разрез, антимонголоидный разрез, узкая глазная щель, микрофтальм, макрофтальм, эпикант, неправильная форма зрачка, поликорнеа.

pom: микростомия, макростомия, высокое небо, уплощенное небо, «карпий рот», неправильная форма зубов.

уши: низкое стояние, ассиметричное расположение, различная величина, большие оттопыренные, разновеликие ушные раковины, аномалия строения завитка и противозавитка, приросшая мочка, расщепленная мочка, микроотия.

шея: короткая, крыловидные складки, кривошея.

туловище: длинное, короткое, деформации грудной клетки, большое расстояние между сосками, низкое стояние пупка, пупочная и паховая грыжи.

кисти: брахидактилия, аранходактилия, синдактилия, клинодактилия, короткий изогнутый V палец, маленькие ногти на всех, одном или нескольких пальцах, обезьянья (поперечная) борозда ладони.

cmonbl: двузубец, трезубец, сандалевидная щель, арахнодактилия, синдактилия, брахидактилия, плоская стопа, греческая стопа, большой первый палец, пальцы находят друг на друга, маленькие ногти на всех или одном пальцах стопы. 
кожа: гемангиомы, депигментированные и гиперпигментированные пятна, избыточное оволосение, атрофические стрии на спине, бедрах, животе, большие родимые пятна.

спина: плоская, с искривлениями.

сердие (на основе данных медицинских карт): боталлов проток, хорда, овальное окно, пролапс митрального клапана.

Статистическую обработку полученных результатов осуществляли с использованием программного обеспечения Microsoft Excel путем расчета среднего арифметического (M), стандартной ошибки средней $(\mathrm{m})$, среднеквадратического отклонения (SD). Достоверность полученных данных определяли с помощью оценки значимости различий средних величин по t-критерию Стьюдента.

\section{Результаты и обсуждение}

Результаты проведенных наблюдений свидетельствуют о том, что у $60 \%$ (n $=63)$ студентов имеет место наличие стигм дизэмбриогенеза, при этом средняя частота встречаемости МАР у одного обследуемого составила $3,17 \pm 0.52$, что соответствует низкому уровню стигматизации (от 0 до 5 МАР) (Бутвиловский, Бутвиловский, Давыдов, 2010).

У обследуемых студентов было обнаружено 37 видов МАР в различных анатомо-топографических областях тела. Количество МАР у одного студента варьировало от 0 до 7. Низкий уровень стигматизации (0-5 стигм) был выявлен у 88.9\% студентов, средний уровень (6-9 стигм) - у 11.1\% обследованных. Наиболее частыми стигмами дизэмбриогенеза в обследованной группе оказались: аномалии стоп и кистей $-31.93 \%$; ушных раковин $-26 \%$; позвоночника $-10.47 \%$, а также формы зубов $-8.37 \%$ и прикуса $-3.14 \%$.

Анализ внутригруппового распределения обучающихся показал, что у 37 студентов (67.27\%), родившихся и проживающих в городской местности, обнаруживаются МАР, соответственно в сельской, у 26 человек (52\%). Внутригрупповое распределения стигм у обследованных обучающихся позволило установить статистически значимые различия $(\mathrm{p}<0.05)$ по уровню стигматизации среди городских и сельских обучающихся. В частности, средняя величина МАР в группе городских студентов составила $3.71 \pm 0.43$, в то время как в группе сельских $-2.10 \pm$ $0.24\left(\mathrm{t}_{\mathrm{st}}=3.58\right.$, число степеней свободы $\mathrm{f}=61$, критическое значение $\mathrm{t}=2$, при уровне значимости $\alpha=0.05)$. В связи с этим были установлены различия и в уровне стигматизации студентов. Так, в группе городских обучающихся низкий уровень стигматизации был установлен у $86.49 \%$, соответственно средний - у $13.51 \%$. В группе сельских - 92.37\% и 7.63\% соответственно. Следовательно, у городских жителей отмечается более высокий уровень стигматизации и частота встречаемости МАР, чем у сельских. Данный факт может быть следствием более высокой техногенной нагрузки в урбоэкосистемах, где поллютанты оказывают негативное влияние на организмы. При этом следует отметить, что чем на более ранней стадии развития находится эмбрион, тем более уязвимым является он при воздействии неблагоприятных факторов в сравнении с реакциями взрослого организма (Ходос, 1984).

O наличии различий между городскими и сельскими обучающимися свидетельствует также и количество обнаруженных МАР. В частности, в группе городских обучающихся было обнаружено 34 вида дисгенезий, сельских - 28 видов. Отличались выявленные МАР не только количественно, но и качественно. Так, самыми распространенными МАР в первой группе обследованных оказались: спина с искривлениями $-9.23 \%$, неправильная форма зубов - 7.69\% (рис. 1a, 1б). 

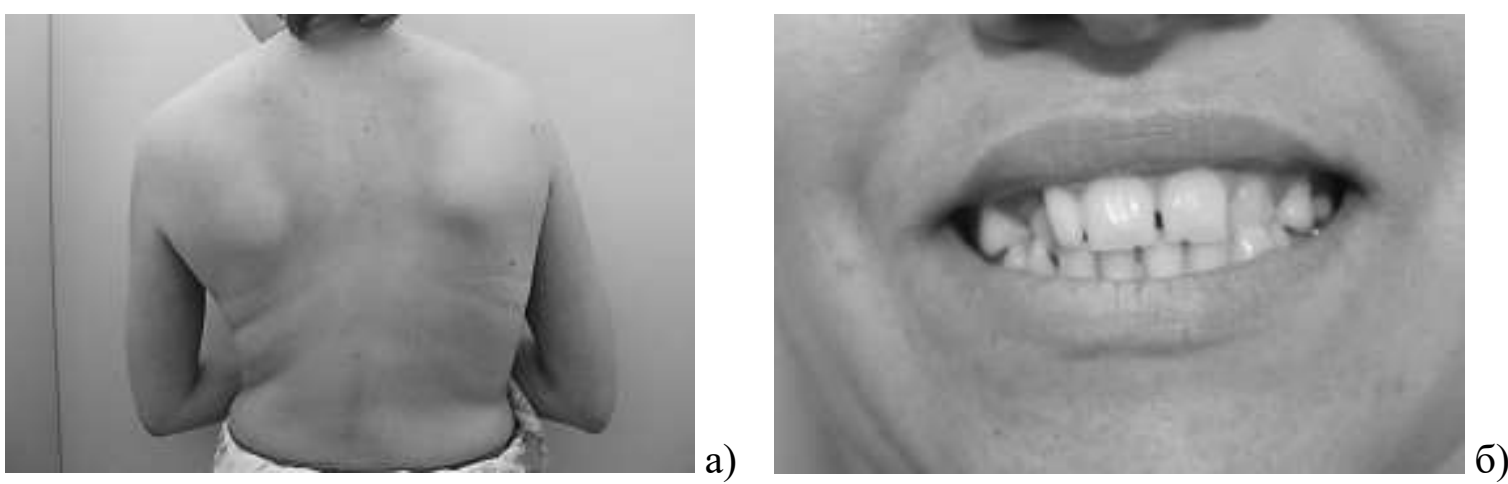

Рис. 1. МАР позвоночника (а) и формы зубов (б)

Большую группу МАР составили аномалии кистей и стоп (в сумме 26.92\%). Характерными аномалиями данной группы оказались: короткий изогнутый $\mathrm{V}$ палец кисти $-5.38 \%$; укороченная (одна или несколько) ногтевая пластина $-4.61 \%$; греческая стопа - 5.38\%; большой I палец стопы, плоская стопа, нахождение пальцев друг на друга - по $3.85 \%$ соответственно (рис. 2 ).
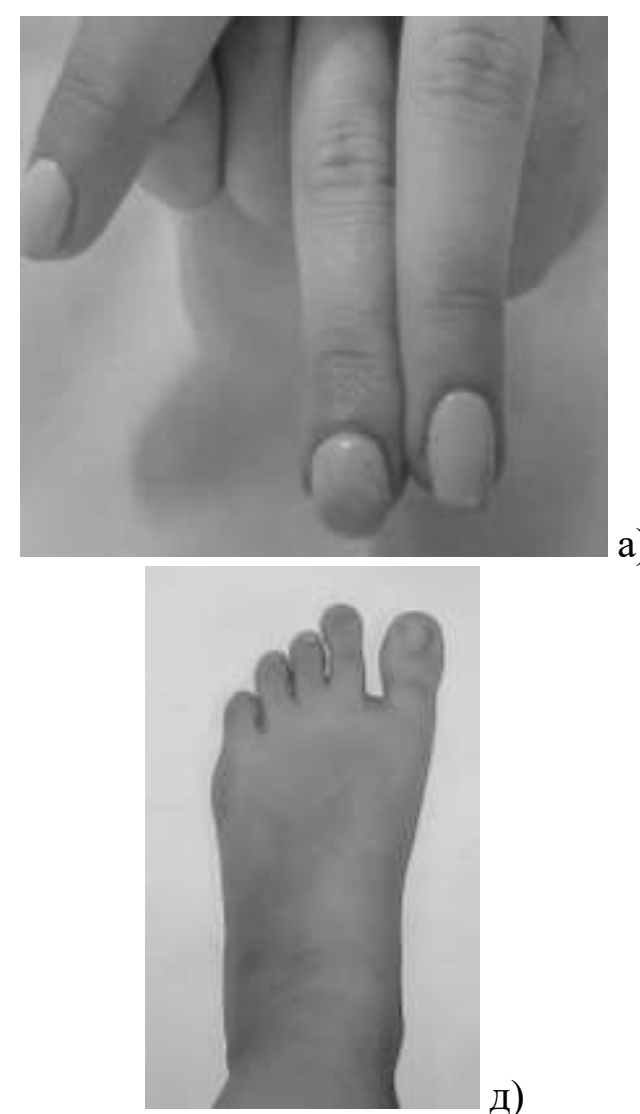

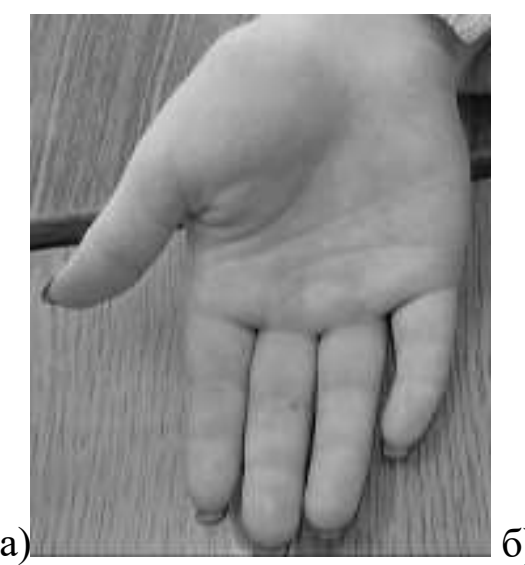

б)
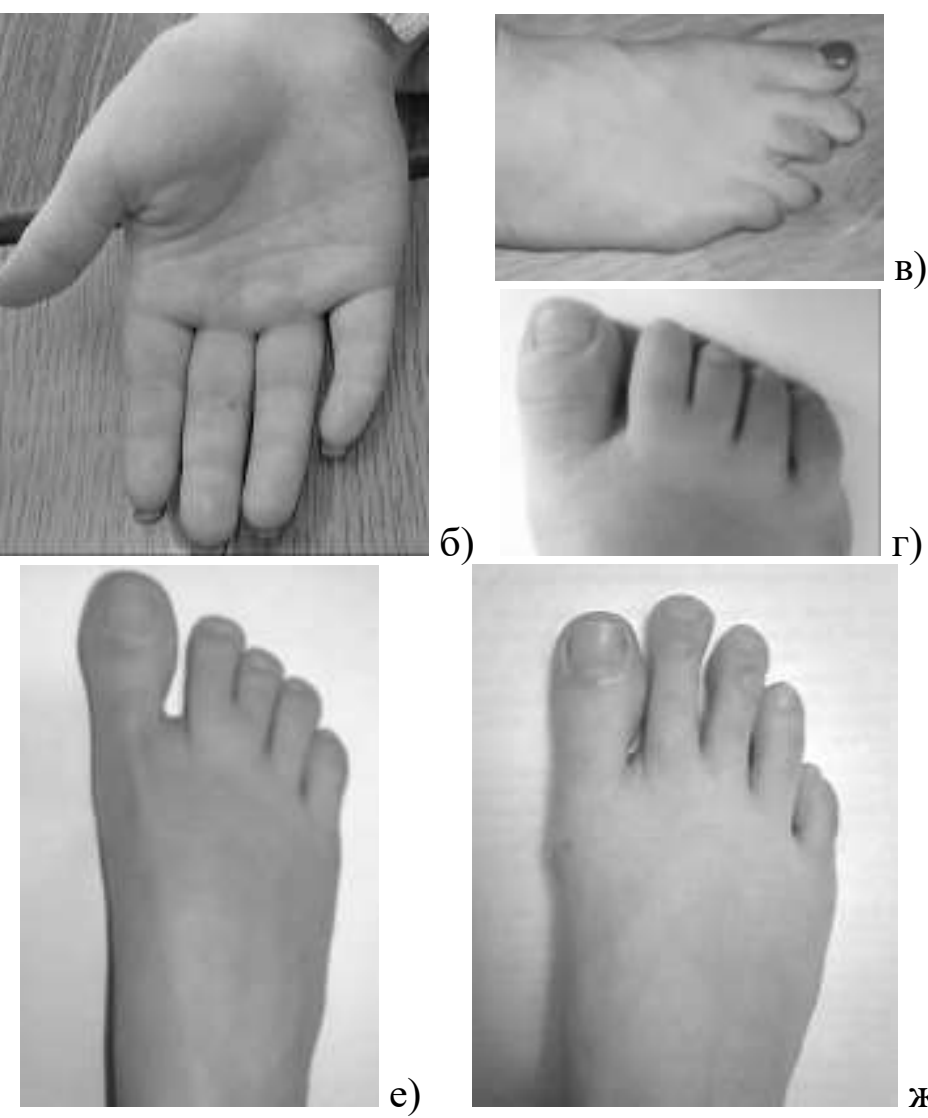

B)

г)

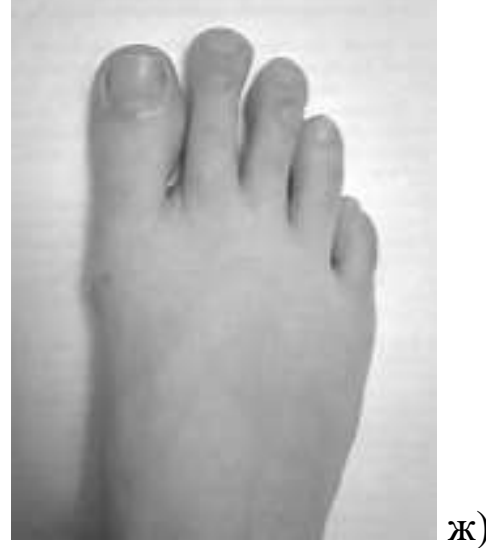

Рис. 2. Малые аномалии кистей и стоп: а - ногтевые пластины различной величины на II пальцах кисти; б - короткий изогнутый V палец кисти; в - нахождение пальцев друг на друга; г - укороченные ногтевые пластины на II и III пальцах стопы; д - сандалевидная щель, е -большой I палец в сочетании с частичной синдактилией II и III пальцев; ж - греческая стопа - длинный II палец

Следующей группой по частоте встречаемости дисгенезий оказались различные аномалии ушных раковин, в частности, были выявлены следующие МАР: приросшая мочка - 4.61\%, асимметричное расположение - 3.85\% и прочие (большие оттопыренные уши, дарвинов бугорок) (рис. 3). 


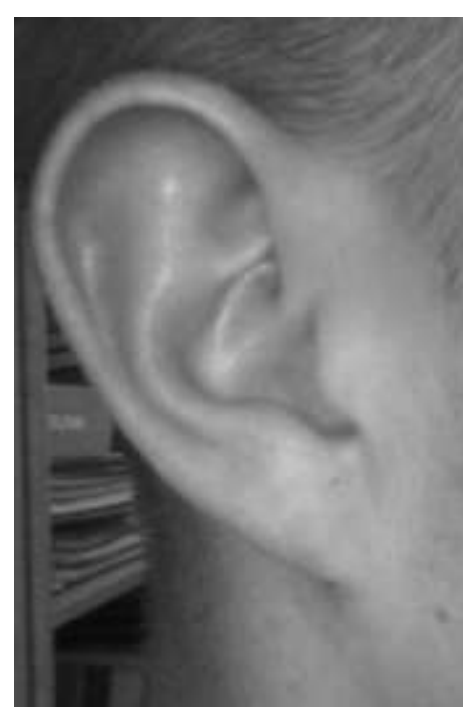

a)
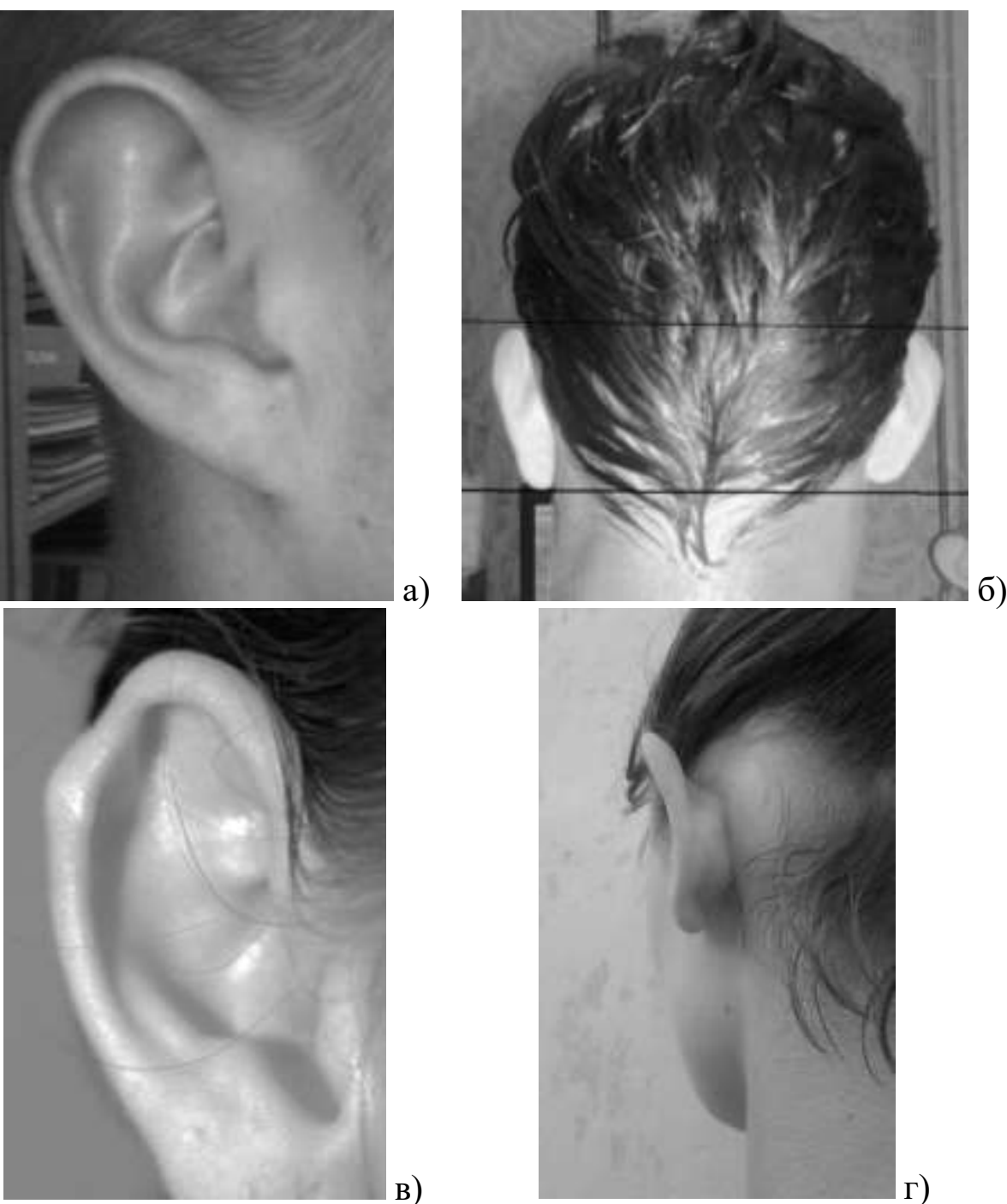

Рис. 3. Малые аномалии развития ушных раковин: а - приросшая мочка; б асимметричное расположение ушных раковин; в - дарвинов бугорок; г - большие оттопыренные уши

В группе сельских обучающихся самыми распространенными оказались аномалии конечностей $-13.11 \%$, в частности, греческая стопа $-8.19 \%$, плоская стопа $4.92 \%$. Следующей по частоте встречаемости МАР в указанной группе была неправильная форма зубов - 9.84\% и в равной степени спина с искривлениями и приросшая мочка - по 6.56\%. Все остальные МАР (короткое или длинное туловище, долихоцефолический череп, высокой небо, большое расстояние между сосками, пороки развития сердца, брахидактилия, арахнодактилия, гетерохромия и др.) встречались гораздо реже $(<5 \%)$.

Сравнительный анализ полученных данных показал, что в обеих группах обследованных студентов самыми распространенными по частоте встречаемости были МАР конечностей, однако в группе городских обучающихся она была в 2.05 раза выше. Аналогичная картина была характерна и для МАР спины, частота встречаемости которой оказалась в 1.45 раза выше у городских обучающихся. Следует отметить, что второй категорией МАР по частоте встречаемости у сельских обучающихся была неправильная форма зубов (9.84\%), а у городских - МАР спины. По-видимому, при повышенном техногенном прессинге увеличивается не только частота проявления MAР, но и степень поражения органов (не зубы, а спина). 
Таким образом выявленные аномалии по частоте встречаемости у городской группы расположились в следующей последовательности: конечности (кисти и стопы $26.92 \%)>$ спина $(9.23 \%)>$ уши $(8.46 \%)>$ зубы $(7.69 \%)$; у сельской группы: конечности $(13.11 \%)>$ зубы $(9.84 \%)>$ спина и уши (по 6.56\%). Следовательно, можно прийти к заключению, что период закладки и формирования конечностей является очень уязвимым этапом перинатального онтогенеза к действию экзогенных и эндогенных факторов. В урбоэкосистемах частота встречаемости МАР конечностей в два раза выше, чем в сельской местности. Аналогичная ситуация оказалась характерной и для МАР спины, следовательно, опорно-двигательный аппарат характеризуется большей степенью повреждения при техногенном загрязнении.

\section{Выводы}

Результаты проведенных наблюдений свидетельствуют о том, что 60\% (n = 63) обследованных студентов имеют МАР, средний показатель которых составил $3.17 \pm$ 0.52 , что соответствует низкому уровню стигматизации. Анализ внутригруппового распределения МАР у обучающихся показал, что они обнаруживаются у 37 студентов, родившихся и проживающих в городской местности, и у 26 студентов, родившихся в сельской.

Наиболее распространенными МАР у городских студентов оказались аномалии конечностей, спины, ушей и зубов. Характер МАР сельских обследуемых был несколько иным, в частности, наиболее распространенными МАР оказались аномалии конечностей и зубов. Сравнительная оценка частоты встречаемости стигм дизэмбриогенеза у городских и сельских студентов, позволила установить более высокий показатель стигматизации у первой группы обследуемых (67.27\%), в то время как у представителей второй группы он составил 52\%. Статистически значимые отличия показателей частоты встречаемости МАР у городских и сельских учащихся позволили прийти к заключению, что городская среда, отличающаяся более высоким уровнем техногенного загрязнения, оказывает выраженное неблагоприятное воздействие на перинатальный этап развития организма. При этом наиболее уязвимой физиологической мишенью к действию экзогенных (средовых) факторов является период закладки и формирования конечностей.

Благодарность. Автор выражает благодарность студентам, принявшим участие в исследовании и предоставившим фотографии МАР.

\section{Список литературы}

1. Бутвиловский В.Э., Бутвиловский А.В., Давыдов В.В. Семиотика наследственных болезней. Стигмы дизэмбриогенеза // Военная медицина. - 2010. - № 3. - С. 106108.

2. География Крыма: Учеб. пособ. для учащ. общеобразоват. учеб. заведений / Л.А. Багрова, В.А. Боков, Н.В. Багров. - К.: Лыбидь, 2001. - 304 с.

3. Ібрагімова E.E. Екологічна оцінка дії техногенних хімічних забруднень на цитогенетичні показники вищих рослин в умовах Криму: Автореф. дис. ... канд. біол. наук: 03.00.16. - КНУ. Київ, 2008. - 20 с.

4. Хаџкель С.Б, Клиценко О.А., Павлов Ю.В. Клиническое значение уровня стигматизации у детей раннего возраста [Электронный ресурс]. - Режим доступа: http://medresurs.in/publ/pediatrija/klinicheskoe_znachenie_urovnja_stigmatizacii_u_detej _rannego_vozrasta/26-1-0-90. 
5. Ходос Х.Г. Малые аномалии развития и их клиническое значение. Иркутск: Восточно-Сибирское книжное изд-во, 1984. - 85 с.

6. Шибанов С.Э. Основные экологические проблемы Крыма // Матер. II Міжн. наук.практ. конф. "Сучасні наукові дослідження - 2006”. - 2006. - Т. 18. Екологія. - С. 24-26.

7. Экология Крыма. Справочное пособие / Под ред. Н.В. Багрова и В.А. Бокова. С.: Крымское учеб.-педагогич. гос-ное изд-во, 2003. - 360 с.

\title{
COMPARATIVE EVALUATION OF THE LEVEL OF STIGMATIZATION OF RURAL AND URBAN LEARNERS AS A CRITERION OF UNFAVOURABLE INFLUENCE OF ANTHROPOGENIC POLLUTION Ibragimova E.E.
}

\author{
Crimean Engineering and Pedagogical University, Simferopol, Russian Federation
} e-mail: evelinabiol@mail.ru

The article deals with the data of a comparative evaluation of the level of stigmatization of learners who were born and raised in urban and rural areas. Statistically significant differences were identified both in the frequency of occurrence of small anomalies of development as well as in the level of stigmatization of the examined students. In particular, in the group of urban students the frequency of occurrence of small anomalies of development made up $67.27 \%$, whereas rural students $-52 \%$. The average level of stigmatization in the first group made up $3.71 \pm 0.43$, in the second $-2.10 \pm 0.24(\mathrm{p}<0.05)$.

The examined students had differences in the number of demonstrated dysgenesis. Therefore, in the group of urban students there were 34 types of small anomalies of development, and in the rural group there were 28 species respectively. The most widespread dysgenesis of urban students there were anomalies of the limbs, back, ears and teeth. The varieties of small anomalies of development of rural students were somewhat different, since in this group the most peculiar there were anomalies of limbs and teeth. Statistically significant differences of indexes of frequency of occurrence of small development anomalies of urban and rural students led to the conclusion that the urban environment, which is characterized by a higher level of anthropogenic pollution, has an unfavorable influence on the perinatal stage of the organism development.

The received data indicate that the period of formation of the structures of the musculoskeletal system is a very vulnerable period of perinatal ontogenesis to the negative influence of exogenous factors.

Key words: small developmental anomalies, students, urban, rural, limbs, ears, perinatal ontogeny, stigmas of dysembryogenesis, dysgenesis.

Поступила в редакциию 19.02.2018 г. 